\title{
Biochemical basis of systemic acquired resistance induced by different Systemic Acquired Resistance (SAR) elicitors in Brassica cultivars challenge inoculated with downy mildew pathogen
}

\author{
Astha* \\ Department of Plant Pathology, Punjab Agricultural University, Ludhiana-141004 (Punjab), \\ India

\section{P. S. Sekhon} \\ Department of Plant Pathology, Punjab Agricultural University, Ludhiana-141004 (Punjab), \\ India \\ *Corresponding author. Email: astha-asr@pau.edu
}

\section{Article Info}

https://doi.org/10.31018/ jans.v13i1.2548

Received: February 4, 2021

Revised: March 5, 2021

Accepted: March 11, 2021

\section{How to Cite}

Astha and Sekhon, P.S. (2021). Biochemical basis of systemic acquired resistance induced by different Systemic Acquired Resistance (SAR) elicitors in Brassica cultivars challenge inoculated with downy mildew pathogen. Journal of Applied and Natural Science, 13(1): 301 - 307. https://doi.org/10.31018/jans.v13i1.2548

\begin{abstract}
In India, Brassica is attacked by many bacterial, fungal and viral pathogens causing various diseases among which, downy mildew caused by Hyaloperonospora brassicae, an oomycete is the most severe one. The present investigation was conducted to reduce fungicide load on Brassica by testing an alternate method of disease control. Different Systemic Acquired Resistance (SAR) compounds were tested as foliar sprays like Salicylic acid, Jasmonic acid and Bion (Benzothiadiazole-BTH) for inducing resistance in different genotypes of Raya (Brassica juncea) against downy mildew pathogen. Protein content in plants ranged between 43.5 to $57.7 \mathrm{mg} / \mathrm{g}$ fresh weight compared to $37.2 \mathrm{mg} / \mathrm{g}$ fresh weight in control. Induction of proteins and defense related enzymes was systemic in nature. The SAR compounds also surged the levels of defense related proteins, i.e. Polyphenol oxidase (PPO), Phenylalanine ammonia lyase (PAL) and pathogenesis related Pr- proteins i.e. $\beta-1,3$ glucanase, Peroxidase (POD), from 21 to 130 per cent indicating induction of resistance. Protein profiling of treated Brassica plants was also done electrophoreticaly, which further confirmed the induction of pathogenesis-related proteins ranging from $15-75 \mathrm{kDa}$ along with

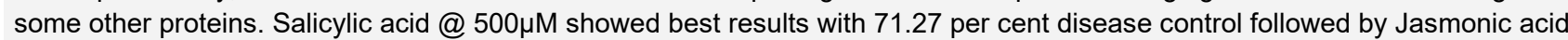
with 69.6 per cent; whereas both, Bion and Beta amino butyric acid gave almost 63 per cent disease control as compared to control plants. Integration of disease tolerance in Brassica varieties/genotypes combined with prophylactic spray of salicylic acid proved to be very economical for managing downy mildew disease.
\end{abstract}

Keywords: $\beta$-amino butyric acids (BABA), Benzothiadiazole (BTH), Brassica, Downy mildew, Jasmonic acid, Salicylic acid, Systemic acquired resistance

\section{INTRODUCTION}

Hyaloperonospora brassicae, the causal agent of downy mildew in Brassica, has a wide host range. Indian mustard (Brassica juncea (Linn.) Czern. and Coss.) is a principle oilseed crop grown in different tropical and subtropical areas of the world. It yields crucial edible oil, which cannot be easily substituted. The limitations in growing mustard are high incidence of diseases and non-availability of high yielding varieties suitable for high input conditions and fluctuations in weather conditions (Kumar, 1999). Among diseases such as white rust (Albugo candida (Pers.) (Kuntze), downy mildew
(Peronospora parasitica (Pers.) (de Bary) play a prominent role in reducing the yield of mustard. White rust and downy mildew collectively caused 37- 47 per cent lesser pods and $17-32 \%$ reduced seeds in mustard ( Keinath, 2015). Downy mildew is known to occur in all major rapeseed-mustard growing states in India (Saharan, 1997 ). Utilizing signaling molecules is very effective in managing plant diseases. Jasmonic acid (JA), Salicylic acid (SA) and $\beta$-Amino butyric acid (BABA), MeJA, calcium chloride, chitosan, gibberellins, ethylene, abscisic acid and even stress can induce defense related proteins. Enkerli et al. (1993) studied the induction of systemic acquired resistance (SAR) in 
many crops by activating various genes coding for PRproteins e.g. $\beta-1,3-$ glucanase (PR-2), chitinase (PR-3), peroxidase (PR-9) and a number of other proteins in stress conditions. Durrant and Dong (2004) explained the mechanism SAR, as induced defense that inculcate long lasting protection against broad spectrum of pathogens. Many synthetic or natural compounds with no direct anti-microbial effect such as INA, potassium salts, and BABA were reported to induce SAR in plants (Oostendorp et al., 2001). Zimmerli et al. (2000) showed the effectiveness of BABA-IR against Botrytis cinerea and $H$. parasitica and Plectosphaerella cucumerina. BTH, an analogue of SA helps in the signal transduction pathway of SAR, cell wall strengthening, along with inciting phytoalexin accumulation, and pathogenesis related (PR) protein synthesis. The present investigation was conducted to evaluate the application of different SAR elicitors i.e. Jasmonic acid (JA), Salicylic acid (SA) and Benzothiadiazole (BTH) and $\beta$ Amino butyric acid (BABA) to induce resistance in Brassica plants to manage downy mildew disease and to reduce fungicide load on Brassica crop by testing different combinations of elicitors along with fungicides.

\section{MATERIALS AND METHODS}

\section{Standardizations of concentrations of SAR elicitors} Three varieties of Raya, i.e., RLC-1 (Moderately Resistant), PBR-97 (Moderately Susceptible) and PBR-91 (Susceptible) were obtained from the Department of Plant breeding (oilseed section), Punjab Agricultural University, Ludhiana, Punjab, India. These procured seeds of different varieties of Raya were grown on $4 \mathrm{X}$ $4 \mathrm{~m}$ wide beds and replicated thrice using standard package of practices in the month of November for three consecutive years (2016 to 2018). Different concentrations of Jasmonic acid and Salicylic acid, Benzo-

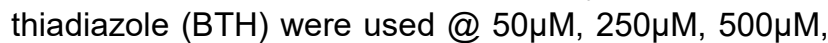
$1000 \mu \mathrm{M}$ for standardization and for Beta amino butyric acids (BABA) concentration levels @ 20 mM, 30mM, 50 $\mathrm{mM}, 100 \mathrm{mM}$ were evaluated for the initiation and upregulation of proteins in cultivars of Raya. All selected concentrations of elicitors were tried as a spray (Prepared in $500 \mathrm{ml}$ of double distilled water for 30 plants i.e. 10 plants in each replication). These concentrations were sprayed on 21 days old plants using an atomizer. Double distilled water sprayed plants were kept as a control in all analogous varieties.

\section{Estimation of total soluble proteins}

Leaf sampling was done on daily basis up to seven days after elicitors spray. Samples were transported to Biochemistry laboratory under refrigerated conditions and to avoid denaturation of proteins they were stored at $-80^{\circ} \mathrm{C}$ in the deep freezer. Protein estimation was done by methodology by Lowry et al. (1951). Bovine serum albumin
(BSA) was run as standards and final protein content was estimated as $\mathrm{mg} / \mathrm{g}$ Fresh weight of tissue.

\section{Protein profiling}

Protein profiling was done by sodium dodecyl sulphatepolyacrylamide gel electrophoresis - SDS-PAGE (Walker, 1996) for treated leaves of three varieties of Raya sprayed with standardized best concentration, which was $500 \mu \mathrm{M}$ in case of SA, JA, BTH and $50 \mathrm{mM}$ in case of BABA. Protein bands from treated varieties were compared with bands of their respective controls. Standard protein marker ladder was also run with molecular weights ranging from 6-180 kDa.

\section{Estimation of enzymes}

Leaf tissue $(100 \mathrm{mg})$ from each plant was extracted in the presence of $1 \%$ polyvinyl-pyrrolidone (PVP). The procedure by Claiborne and Fridovich (1979) was employed for the estimation of Peroxidase, for Phenylalanine ammonia lyase methodology by Burrell and Rees (1974) was used and for Polyphenol oxidase, the standard methodology by Zauberman et al. (1991) was applied. For estimation of b-1, 3 glucanase, Dinitrosalicylic acid (DNSA) was used as a reagent using standard protocol by Kauffman et al. (1987).

\section{Estimation of chlorophylls}

Chlorophylls were estimated, using $0.2 \mathrm{~g}$ of leaf sample in $1 \mathrm{~mL}$ of Dimethyl Sulfoxide (DMSO) by employing the methodology of Barnes et al. (1992)

\section{Determination of disease severity}

Elicitors were sprayed after 21 days of sowing, followed by $\mathrm{H}$. Brassicae pathogen inoculations made after 2 days of elicitor spray, maintaining high relative humidity for next 4 days to create disease. Per cent disease incidence and disease severity was observed from 7 to 14 days post challenge inoculation. The leaves were collected for one week on daily basis after disease inoculation and various biochemical studies were done. The Statistically (CRD factorial ANOVAs) at the significant difference (CD 5\%) in all biochemical data was observed after elicitor treatment. Data in tables and figures are means of seven readings taken at 24 hours interval up to a week post-challenge inoculation.

\section{Determination percent disease control}

These four elicitors were tested in various combination treatments along with fungicides to have better disease control. Only best selected doses showing peak protein induction of SA, JA, BTH and BABA were used for disease control, then second treatment was planned in the combination of a fixed dose of contact fungicide, i.e. Mancozeb @ $350 \mathrm{~g}$ per acre. Best concentrations of elicitors were also tested in combination with systemic fungicide i.e. Ridomil MZ @ 350 g per acre (lower dose 
of fungicide). One treatment for standard fungicide control practice was also followed using both contact and systemic fungicide. Total three sprays were given out of which first spray of prophylactic i.e. before the onset of disease, followed by disease inoculations. The two sprays of different combinations were given at weekly interval.

\section{RESULTS AND DISCUSSION}

\section{Proteins}

Data of elicitors spray on different Raya varieties namely, RLC-1 (MR), PBR-97 (MS) and PBR-91 (S) are given in Fig 1. Maximum protein induction (Mean) was observed at $500 \mu \mathrm{M}$ of SA in RLC-1 i.e. $57.6 \mathrm{mg} / \mathrm{gFW}$ followed by $57.1 \mathrm{mg} / \mathrm{gFW}$ in PBR-97 and $53.2 \mathrm{mg} / \mathrm{gFW}$ in PBR-91. JA treatment gave mean maximum protein induction observed in RLC-1, i.e. $55.6 \mathrm{mg} / \mathrm{gFW}$ followed by PBR-97 and PBR-91. BTH and BABA were in parity with each other in protein induction.

\section{Phenylalanine ammonia lyase (PAL) and Peroxi- dase (POD) activity}

In the context of variety PBR-97; SA caused $78 \%$ increase in PAL activity in leaves, whereas JA caused $65 \%$, BABA showed $53 \%$ and BTH showed $41 \%$ spike in PAL activity w.r.t control (Fig. 2). Similarly, in RLC-1, SA caused $89 \%$ increase in PAL activity in leaves, whereas $\mathrm{JA}$ resulted in $62 \%$, BABA gave $51 \%$ and $\mathrm{BTH}$ showed $41 \%$ increase in PAL activity w.r.t control. Similar pattern was observed for Peroxidase (POD) activity. The PAL activity showed spike upto $4^{\text {th }}$ day post elicitor treatment.

\section{$\beta-1,3$ glucanase and Polyphenol oxidase (PPO) activity}

Amongst the different elicitors treatment in PBR-97; SA treatment showed the spike of $37 \%$ in $\beta-1,3$ glucanase activity in leaves, followed by JA and BABA, which resulted in $22 \%$, whereas BTH showed $19 \%$ increase in $\beta-1,3$ glucanase activity w.r.t control. Similarly, in variety RLC-1 SA caused $47 \%$ increase in $\beta-1$, 3 glucanase activity in leaves, whereas JA resulted in $33 \%$, BABA gave $27 \%$ and BTH gave $17 \%$ increase in $\beta-1,3$ glucanase activity w.r.t control (Fig. 3). Elicitors have a similar pattern in PBR-91. Similarly, in RLC-1 SA caused $130 \%$ increase in PPO activity raya leaves, JA resulted in $103 \%$, BABA treatment $82 \%$ and $\mathrm{BTH}$ gave $72 \%$ increase in PPO activity w.r.t control. Similar pattern was seen in all varieties (Fig. 3). The elicitors showed spike up to $4^{\text {th }}$ day post treatment. The figure showed that SA was more effective in increasing PPO activity as compared to all other elicitors.

\section{Total chlorophyll}

The plants were sprayed with elicitors, after 21 days of planting and were further, challenge inoculated with pathogen after 2 days of elicitor spray. In RLC1 ; SA showed spike of $16 \%$ whereas JA showed only $2 \%$ increase in chlorophyll , BABA gave $13 \%$ and BTH showed $12 \%$ spike in chlorophyll (mg/g FW) content w.r.t control (Fig. 4). Similarly, in PBR-97; SA spiked the pigment levels to $13 \%$ whereas JA resulted in only $3 \%$ increase, BABA gave $11 \%$ and BTH gave $9.5 \%$ increase in total chlorophyll (mg/g FW) content w.r.t control. An increase in chlorophyll content in JA treat-

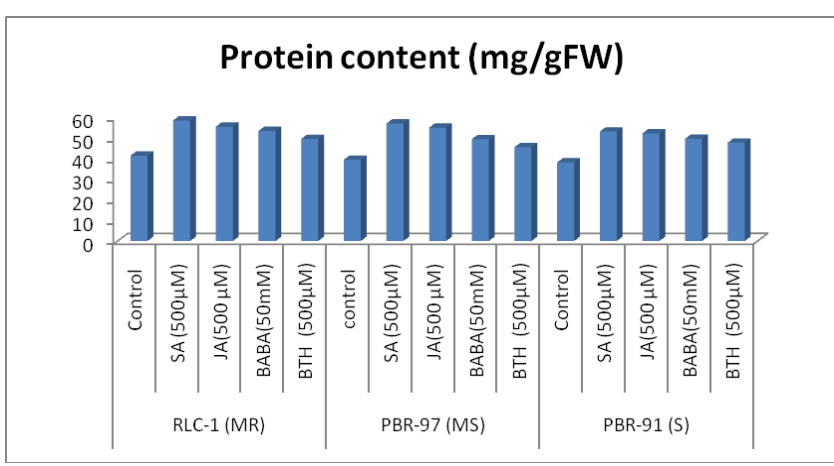

Fig. 1. Effect of different doses of elicitors for maximum induction and overexpression of total soluble protein content ( $\mathrm{mg} / \mathrm{g} \mathrm{FW}$ ) in Raya varieties.

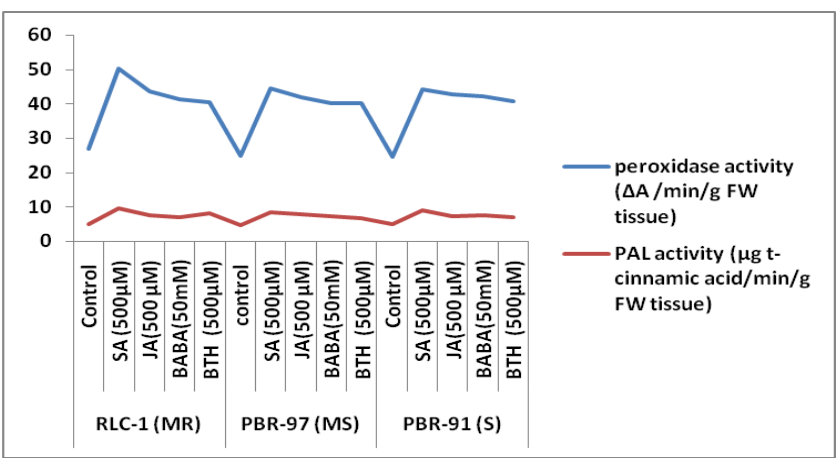

Fig. 2. Effect of foliar spray with different elicitors' i.e. SA and $J A, B A B A$ and $B T H$ on peroxidase activity $(\triangle A / \mathrm{min} / \mathrm{g}$ FW tissue) and on PAL activity ( $\mu$ g t-cinnamic acid/min/g FW tissue) in leaves of Raya varieties challenge inoculated by H. Brassicae.

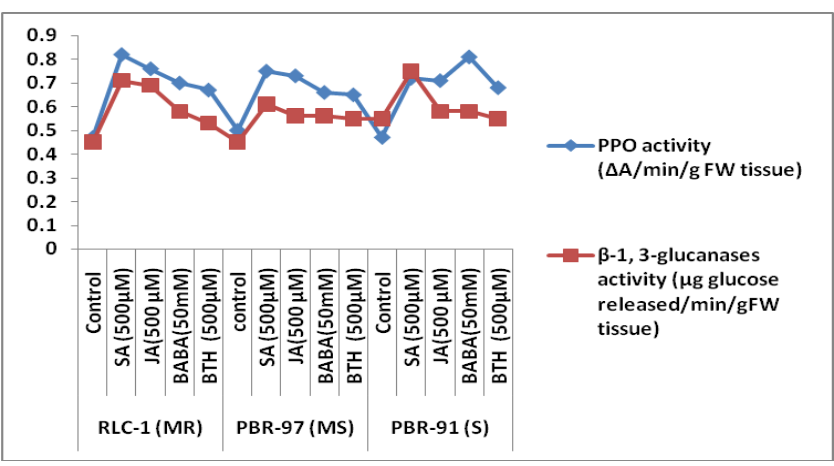

Fig. 3. Effect of foliar spray with different elicitors i.e. $S A$ and $J A, B A B A$ and $B T H$ on $\beta-1,3-$ glucanases activity ( $\mu g$ glucose released/min/gFW tissue) and on PPO activity $(\triangle A / \mathrm{min} / \mathrm{g} \mathrm{FW}$ tissue) in leaves of Raya varieties challenge inoculated by $H$. Brassicae. 


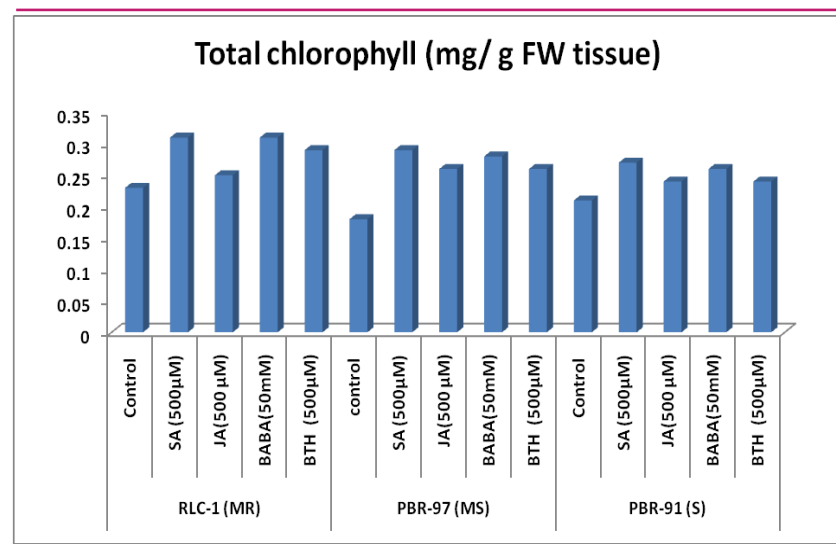

Fig. 4. Effect of foliar spray with different elicitors i.e. $S A$ and JA, BABA and BTH on total chlorophyll (mg/ $g$ FW tissue) in leaves of different Raya varieties.

ment was at par with control plants. The highest value of total chlorophylls content was recorded in the sample collected after $4^{\text {th }}$ day of elicitor treatment.

The spray of MeJA or SA significantly increased photosynthetic pigments content in cucumber leaves, this increase is connected with the induction of Reactive oxygen species and other oxidations factors ( Farouk et al., 2008). Cag et al. (2009) studied the effect of SA, applied exogenously on sunflower seedlings, cotyledons and increased levels of chlorophyll, carotenoids, protein contents and PO activity were recorded. Khodary (2004) observed the increase in chlorophyll and carotenoid contents at $0.5 \mathrm{mM} \mathrm{SA}$ and $0.25 \mathrm{mM} \mathrm{MJ}$ application maize plants that were salt stressed

Boller (1993) showed the induction of chitinases and $\beta$ 1, 3- glucanases and different enzymes in various plant genotypes in reaction to infestation by pathogens, elicitor or chemical treatments. Tomato seedlings treated with Trichoderma asperellum showed increased activity of various defense related enzymes i.e. peroxidase (POD), polyphenol oxidase (PPO), phenylalanine ammonium lyase (PAL), $\beta-1,3$-glucanase and such plants were more resistant against Ralstonia solanacearum in comparison to the tomato seedlings which were not treated with biocontrol agent indicated reduced activity of all these defense related enzymes (Murthy et al 2013). Aldesuquy (2015) studied the effect of SA application in Vicia faba against Botryis and showed that there was an increase in the total soluble protein content. Ding et al. (2002) observed that Pretreating fruits of tomato with Methyl JA instigated the production of some PR proteins such as Pr-2b, PR-2a, Pr-3b etc., which resulted in chilling tolerance and resistance to pathogens and reducing the incidence of decay.

In the present investigations Raya plants showed spike in the activities of defense related proteins and enzymes after usage of various elicitors as compared to control. A further supplementary rise in the activities was noticed upon disease inoculation. The biochemical defense response was better in the case of combined treatment of elicitors and pathogen, because the plant gets primed upon prior treatment of elicitor. SAR in plant is not directly activated upon first exposure to stimulus; but it needs priming and mostly there is faster and stronger induction of the plant defense on subsequent exposure to abiotic and/or biotic stress (Conrath 2011). Elicitors alone without challenge inoculation of $P$. cubensis primed the plants but biochemical activity showed higher response with a combined effect of elicitor plus pathogen (Table 1). Out of the various elicitors used, SA followed by JA, BABA and BTH proved to be more effective in eliciting the level of enzymes imparting defense; in Raya against downy mildew pathogen.

\section{Electrophoretic study (SDS-PAGE) of protein ex- tract of different Raya cultivars}

PR proteins (Acidic extracellular forms) built up at the onset of plant resistance, depicting that they have a role as molecular markers for SAR expression. Thermostable, highly resistant to proteases, PR proteins have low molecular weight (5-75 kDa), and they are, extractable and stable at low $\mathrm{pH}(<3)$. PR proteins are known to provide resistance against many pathogens. Electrophoretic study of Raya varieties' protein pattern in response to $500 \mu \mathrm{M}$ of JA, SA and BTH and $50 \mathrm{mM}$ of $B A B A$, resolved in the molecular weights ranging from 6-180 kDa with respect to standard protein markers. Distinct bands in the range of 6-75 kDa were observed in elicitor treated leaf samples as compared to their respective control (Plate 1). It is known that PR proteins fall under the range of $15.5 \mathrm{KDa}$ to $75 \mathrm{KDa}$ (Van Loon et al., 2006), which signified that application of SA, JA, $B A B A$ and $B T H$ in Raya resulted in PR protein induction along with some other proteins.

\section{Disease data}

Evaluation of SAR inducers, i.e. SA, JA, BABA and $B T H$ in various combination treatments, was done to have better downy mildew control in Raya variety PBR91. All the treatments gave $100 \%$ disease control up to seven days of challenge inoculation. Per cent disease control varied from $74 \%$ in $\mathrm{BTH}$

treated plots to $95 \%$ in standard recommended fungicide treatment. Maximum Per cent disease control at $94 \%$ was given by the recommended spray schedule of Mancozeb and Ridomil Gold. SA treatment in series with a systemic fungicide, i.e. Ridomil gold, gave 92.25 $\%$ disease control at par with the second best treatment. SA singly gave $82.6 \%$ disease control whereas in combination with Mancozeb gave $87.2 \%$ respectively. All the four elicitors, i.e. SA, JA, BABA and BTH gave more than $74 \%$ disease control when applied singly as 
a foliar spray on potato at the weekly interval, whereas they gave disease control more than $85 \%$ when applied in spray schedule with Mancozeb. When these SAR elicitors were applied in spray schedule followed by half dose Ridomil gold, more than $90 \%$ disease control was observed, which was at par with recommended fungicide disease control. Therefore, it can be concluded that SA treatment can be combined with half dose of systemic fungicide Ridomil for controlling downy mildew of Raya.

Ziadi et al. (2001) reported that foliar application of BTH induces systemic resistance in many crops and higher activity of $\beta-1,3$-glucanases was observed. He tested ASM, an analogue of the BTH, on cauliflower ( $B$. oleracea var. botrytis) seedlings for inducing resistance against downy mildew ( $P$. parasitica. Therefore, in certain cases, instead of using conventional chemical fun-

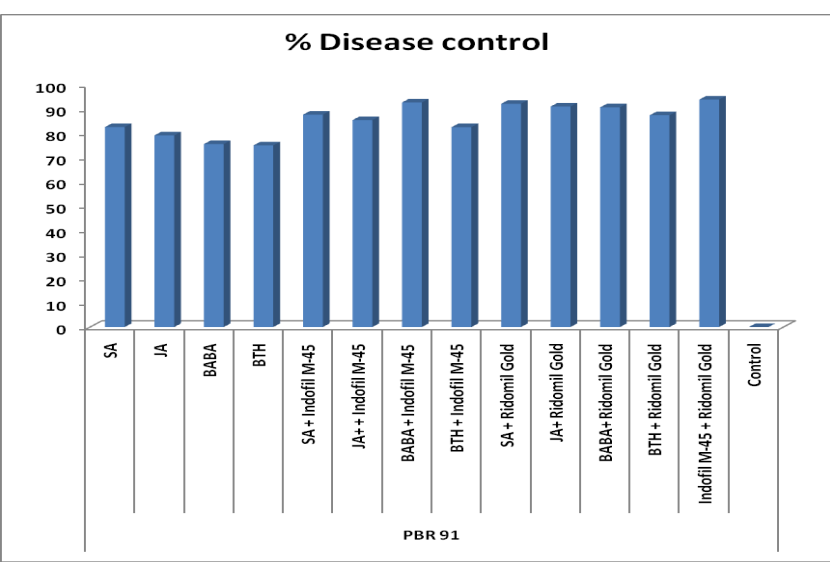

Fig. 5. Testing efficacy of elicitors along with Ridomil gold and Indofil M-45 against disease severity of Downy mildew of Brassica.

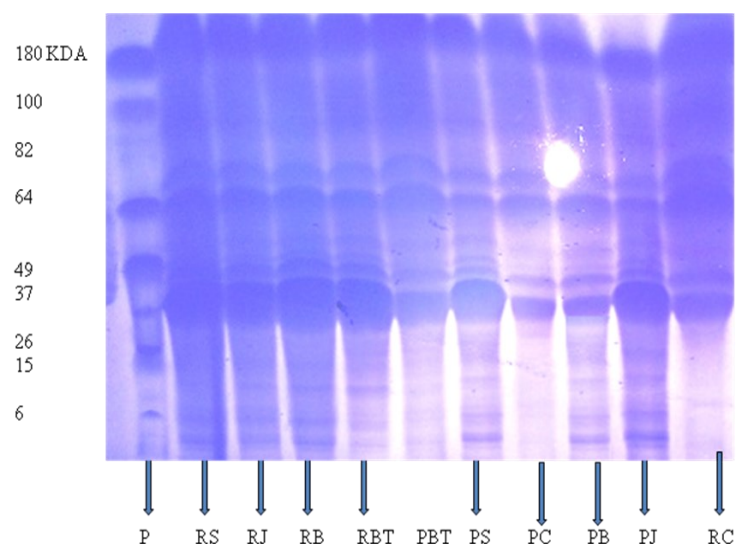

Plate 1. P- Protien ladder, RS: RLC-1 Variety treated with $500 \mu M$ SA, RJ: RLC-1 Variety treated with $500 \mu M$ $J A, R B: R L C-1$ Variety treated with 50MM BABA, RBT: $R L C-1$ Variety treated with 250 $\mu$ G/ML BION, PS: PBR-91

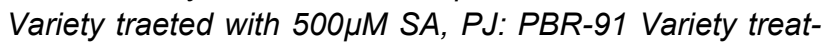

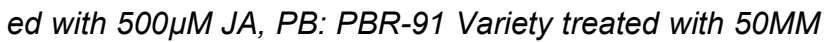
$B A B A, P B T: P B R-91$ Variety treated with $250 \mu \mathrm{G} / \mathrm{ML} B I O N$, RC- RLC-1 Control, PC: PBR-91 Control 
Table 2. Correlation between various enzymes activity, chlorophyll, protein content and disease severity in different varieties of Raya.

\begin{tabular}{lllllll}
\hline $\begin{array}{l}\text { Disease Severity } \\
\text { on variety }\end{array}$ & $\begin{array}{l}\text { Total } \\
\text { protein }\end{array}$ & $\begin{array}{l}\text { b-1, 3 } \\
\text { glucanase }\end{array}$ & Pal & Peroxidase & PPO & Chlorophyll \\
\hline RLC-1 & -0.996 & -0.934 & -0.962 & -0.980 & -0.986 & -0.680 \\
PBR-97 & -0.997 & -0.976 & -0.983 & -0.997 & -0.983 & -0.722 \\
PBR-92 & -0.995 & -0.990 & -0.987 & -0.999 & -0.998 & -0.695 \\
\hline
\end{tabular}

Critical Value of $r$ at $5 \%=0.876$

gicides spray of any of the four elicitors especially $S A$, before the onset of disease to prime the plants can be effectively used for disease control. Gao and Zhang (2013) reported an increase in PPO, PAL, POD activities in pear fruit in response to pear scab rot. Tian et al. (2005) studied that fruits of pear plant when treated with elicitors like SA, oxalic acid, calcium chloride etc reduced the disease incidence of $A$. alternate and significantly enhanced defense-related enzyme activities such as $\beta, 1-3$ glucanase, phenylalanine ammonia lyase, peroxidase, and polyphenol oxidase activity. Peroxidase extracted from Raya leaves were also reported to be acidic and are associated with induced resistance in the plant (Smith and Hammerschmidt, 2007). It could be concluded that primed plants with Salicylic acid act better for suppressing the severity of downy mildew disease of Raya, by stimulating their own inbuilt resistance under field conditions. Moreover, it is considered as safe, cost-effective and easily applied for such diseases. A blanket spray of salicylic acid can be done on vegetable crops before the onset of diseases to enhance plant defense against oomycete pathogens. A blanket spray of salicylic acid (SA) was also tested against late blight potato and downy mildew of muskmelon and it gave good results (Astha et al., 2019). During this study, it was found that enzyme activity was negatively correlated with disease development (Table 2). A negative correlation between bacterial blight disease development and antioxidant enzyme activity was studied by Sharma et al. (2012).

\section{Conclusion}

Our studies indicated that PAL, POX, PPO and $\beta 1$, 3glucanases play an important role in imparting resistance to downy mildew pathogen in Brassica (Raya). Therefore, it can be deduced from the present study that SA treatment can be combined in spray schedule with contact fungicide or with a half dose of systemic fungicide for control of downy mildew in Brassica, which will be economical and as well as ecofriendly hence reducing fungicide load on important oilseed crop. It is concluded that only 8-10 g of SA was used dissolved in 100 liters of water for spraying one acre of Raya crop. It will approximately cost only (INR) Rs 15/
Acre, making it very economical and safe for farmers growing oilseeds worldwide.

\section{Conflict of interest}

The authors declare that they have no conflict of interest.

\section{REFERENCES}

1. Aldesuquy, H. S. (2015). Shikimic acid and salicylic acid induced protection on growth vigor, seed yield and biochemical aspects of yielded seeds of Vicia faba plants infected by Botrytis fabae, J. Pl. Pathol. Microb., 6 (9), 6578.

2. Astha, Sekhon, P. S. and Sangha, M. K. (2019). Influence of different SAR elicitors on induction and expression of PR-proteins in Potato and Muskmelon against Oomycete pathogens. Indian phytopath., 72, 43-51.

3. Barnes, J. D., Balaguer, L., Manrique, E., Elvira, S. and Davison, A. W. (1992). A reappraisal of the use of DMSO for extraction and determination of chlorophyll $a$ and $b$ in lichens and higher plants. Environ. Exp. Bot., 32, 85-100.

4. Boller, T. (1993). Antimicrobial function of the plant hydrolases, chitinase and $\beta-1,3-$ glucanase. In: Firtig $B$ and Legrand M (eds) Mechanisms of Plant Defense Responses, Pp 391-400, Kluwer academic publishers, Netherlands.

5. Burrell, M. M. and Rees, T. A. (1974). Metabolism of phenylalanine and tyrosine by rice leaves infected by Pyricularia oryzae. Physiol. PI. Pathol., 4,497-508.

6. Cag, S., Cevahir, Oz. G., Sarsag, M. and Goren-saglam, N. (2009). Effect of salicylic acid on pigment, protein content and peroxidase activity in excised sunflower cotyledons. Pak. J. Bot., 41,2297-303.

7. Claiborne, S. and Fridovich, I. (1979). Assay for peroxidase. In: Sadasivan and Manickam .ed. Biochemical method Pp 190. New Age International Publisher New Delhi.

8. Conrath, U. (2011). Molecular aspects of defense priming Trends. PI. Sci., 16(10), 524-31.

9. Ding, C., Wang, C. Y., Gross, K. C. and Smith, D. L. (2002) Jasmonates and salicylate induce the expression of pathogenesis-related-protein genes and increase resistance to chilling injury in tomato fruit. Planta., 214, 895901.

10. Durrant, W. E. and Dong, X. (2004). Systemic acquired resistance. Annu. Rev. Phytopathol., 42, 185-209.

11. Enkerli, JU., Gisi, E. and Mosinges, (1993). Systemic acquired resistance to Phytophora infestans in tomato and the role of pathogenesis-related proteins. Physiol. Mol. 
Plant. Pathol. 43, 161-171.

12. Farouk, S., Ghoneem, K. M. and Abeer, A. Ali. (2008). Induction and expression of systemic resistance to downy mildew diseases in cucumber by elicitors. Egypt. J. phytopath., 36, 95-111.

13. Gao, L. and Zhang, Y. (2013). Effect of Salicylic Acid on Pear Leaf Induced Resistance to Pear Ring Rot. Appl. Sci. J ., 22 (11), 1534-39.

14. Kauffman, S., Legrand, M., Geoffroy, P. and Frittig, B. (1987). Biological function of pathogenesis - related Proteins: four PR protein of tobacco have 1,3 beta -glucanase activity. EMBO. J ., 6 (11), 3209-12.

15. Keinath, A. P. (2015). Cucurbit downy mildew management for 2015. Clemson University Cooperative Extension, IL, 90.

16. Khodary, S. E. A. (2004). Effect of salicylic acid on the growth, photosynthesis and carbohydrate metabolism in salt stressed maize plants. Int. J. Agric. Biol., 6, 5-8.

17. Kumar, P. R. (1999). Package of practices and contingency plan for enhancing production of rapeseed-mustard in India. A publ. of the National Res. Centre on RapeseedMustard, Sewar, Bharatpur, pp 1-39.

18. Lowry, O. H., Rosebrough, N. J., Furr, A. L. and Randal, R. J. (1951). Protein measurement with folin-phenol reagent J. Boil. Chem., 193, 265-75.

19. Murthy, K. N., Uzma, F. and Srinivas, C. (2013). Induction of systemic resistance by Trichoderma asperellum against bacterial wilt of tomato caused by Ralstonia solanacearum. Ind.J.Agri.Res., 1, 181-94.

20. Oostendorp, M., Kunz, W., Dietrich, B. and Staub, T. (2001). Induced disease resistance in plants by chemical. Eur. J. Plant. Pathol., 107, $19-28$.

21. Saharan, G. S., Verma, P.R. and Nashaat, N.I. (1997).
Monograph on downy mildew of crucifers.technical bulletin 1997-01, Saskatoon Research Centre, Canada, 197 pp.

22. Sharma, N., Kaur, C., Singh, J. and Gupta, A. K. (2012). Biochemical responses associated with bacterial blight of rice (Oryza sativa). Arch. Phytopath. PI. Protect., 45, 47-61.

23. Smith, J. A. and Hammerschmidt, R. (2007). Comparative study of acidic Peroxidases associated with induced resistance in cucumber, muskmelon and watermelon. Physiol. Mol. Plant. Pathol., 33 (2), 255-261.

24. Tian, S., Wang, Y., Qin, G. and Xu, Y. (2005). Induction of defense against alternaria rot by different elicitors in harvested pear fruit. Appl. PI. Microbial. Biotechnol. 78,1-6.

25. Van Loon, L. C., Rep, M., Pieterse, C. M. (2006). Significance of inducible defense-related proteins in infected plants. Annu. Rev. Phytopathol., 44, 135-62.

26. Walker, J. M. (1996). SDS polyacrylamide gel electrophoresis of proteins. In, Walker J M (ed) The protein protocols handbook. pp 55-61. Humana Press Inc. Totowa N J.

27. Zauberman, G., Ronen, R., Akerman, M., Weksler, A., Rot, I. and Fuchs, Y. (1991). Post-harvest retention of the red colour of litchi fruit pericarp. Scientia. Hort. 47: 89-97

28. Ziadi, S., Barbedette, S., Godard, J. F., Monot, C., L,e Corre. D. and Silue, D. (2001). Production of pathogenesis related proteins in cauliflower (Brassica oleracea var botrytis) downy mildew (Peronosora sparasitica) pathosystems treated with acibenzollar -S- methyl. PI. Pathol ., 50, 579-86.

29. Zimmerli, L., Jakab, C., Metraux, J. P. and Mauch-Mani, B. (2000). Potentiation of pathogen specific defense mechanisms in Arabidopsis by beta-aminobutyric acid. Proceedings of the national academy of sciences of the USA, 97,12929-25. 